\title{
Effect of MRI Scanner Noise on Blood Oxygen Level-Dependent Activation of Cortical and Subcortical Auditory Centers
}

\author{
Tae Su Kim ${ }^{1}$, Natalia Yakunina ${ }^{2}$, Woo-Suk Tae ${ }^{2}$, Eun Kyoung Kang ${ }^{3}$, \\ Sam Soo Kim ${ }^{4}$, Ji-Hoon $\mathrm{Min}^{5}$, and Eui-Cheol Nam ${ }^{6}$ \\ ${ }^{1}$ Departments of Otolaryngology, ${ }^{3}$ Rehabilitation Medicine, Kangwon National University Hospital, Chuncheon; and ${ }^{2}$ Neuroscience \\ Research Institute, Kangwon National University Hospital, Chuncheon; and ${ }^{4}$ Department of Radiology, School of Medicine, Kangwon \\ National University, Chuncheon, Korea; and Department of Biopsychology, Cognition, and Neuroscience, University of Michigan, \\ Ann Arbor, MI, USA; and ${ }^{6}$ Department of Otolaryngology, School of Medicine, Kangwon National University, Chuncheon, Korea
}

\section{대뇌 피질 및 피질하 청각 중추의 활성화에 미치는 MRI 스캐너 소음의 영향}

\author{
김태수 ${ }^{1} \cdot$ Natalia Yakunina ${ }^{2} \cdot$ 태우석 ${ }^{2} \cdot$ 강은경 $^{3} \cdot$ 김삼수 $^{4} \cdot$ 민지훈 $^{5} \cdot$ 남의철 $^{6}$ \\ 강원대학교병원 이비인후과, ${ }^{1}$ 뇌과학연구소, ${ }^{2}$ 재활의학과, ${ }^{3}$ \\ 강원대학교 의학전문대학원 영상의학과교실, ${ }^{4}$ 이비인후과학교실, ${ }^{6}$ 미시간대학교 인지-심리-뇌과학과 ${ }^{5}$
}

\footnotetext{
Received November 13, 2014

Revised December 2, 2014

Accepted December 2, 2014

Address for correspondence

Eui-Cheol Nam, MD, PhD

Department of Otolaryngology,

School of Medicine,

Kangwon National University,

1 Gangwondaehak-gil,

Chuncheon 200-701, Korea

Tel $+82-33-258-2311$

Fax $+82-33-255-8809$

E-mail birdynec@kangwon.ac.kr
}

Background and Objectives We compared functional MRI acquisition methods of sparse temporal acquisition (STA) and continuous acquisition (CA) to estimate the effect of MRI scanner background noise (SBN) on blood oxygen level-dependent (BOLD) activation of cortical and subcortical auditory centers during auditory stimulation.

Subjects and Method Fourteen healthy subjects (eight males, age 30.6 \pm 4.7 years) were presented with classical music in a block paradigm ( $36 \mathrm{~s}$ on/off) in two STA [repitition time (TR)=12 s, 60 volumes] and two CA (TR=2 s, 360 volumes) functional MRI sessions. To account for the sample size difference, an additional volume-matched continuous dataset (CAm) was generated by matching CA to 60 volumes of STA. A group-level analysis based on BOLD activation maps was performed. Percent signal change (PSC), T-statistic values and signal variability in cortical and subcortical auditory regions of interest (ROIs) were calculated from individual activation maps and compared between the STA, CA, and CAm.

Results The group analysis showed activation in the primary and secondary auditory cortices in all datasets. However, the activation of subcortical auditory centers above the accepted threshold was only observed in STA. STA (less SBN) showed higher PSCs and T-statistic values in all ROIs except planum temporale when compared to CAm. However, there was no difference in signal variability among the datasets.

Conclusion Our results suggest that SBN should be considered as a significant confounder in auditory-evoked functional MRI studies particularly in the activation of subcortical auditory centers, and that STA can be an effective imaging method for reducing the effect of SBN. Korean J Otorhinolaryngol-Head Neck Surg 2015;58(2):101-9

Key Words Auditory stimulation · Continuous acquisition · Functional MRI - Scanner background noise $\cdot$ Sparse temporal acquisition.

\section{서 론}

기능적 자기공명영상(functional magnetic resonance im- aging, fMRI)은 방사선 조사의 위험이 없고, 공간 및 시간적 해상력(temporal and spatial resolution)이 뛰어나 대뇌 청각 중추들의 기능적 활성을 연구하는 기법으로 활발하게 사용되 
고 있다. 그러나 기능적 영상(echoplanar image, EPI) 획득기 간 동안 경사자장 (gradient)으로부터 지속적으로 발생하는 MRI 스캐너 배경 소음(MRI-scanner background noise, $\mathrm{SBN}$ )은 특히 청각 자극을 이용하는 청각 fMRI 연구의 가장 큰 장애 요인으로 생각되어 왔다. ${ }^{1)} \mathrm{SBN}$ 은 자극음과는 별도의 청각자극으로 작용하므로 실험에서 의도하는 청각반응에 대 해 차폐(masking), 습관화(habituation), 포화(saturation) 등 의 간섭을 일으키며 자극음에 선택적으로 집중하기 위한 부 가적인 주의집중을 요구하므로 조용한 환경에서 시행된 실험 과 크게 다른 결과를 초래할 수 있다. ${ }^{2)} \mathrm{SBN}$ 은 외부 청각 자극 의 유무와 관계없이 늘 지속적으로 존재하는 소음이므로 단 순히 수학적 감산으로 $\mathrm{SBN}$ 효과를 제외시켜 의도된 청각자 극 효과만을 fMRI 결과에서 추출할 수 있다는 주장은 청각 반응들 사이의 이러한 상호작용을 이해하지 못한 결과이므로 $\mathrm{SBN}$ 의 영향을 최소화하기 위한 별도의 노력이 반드시 필요 하다. MRI 스캐너 자장의 세기가 커질수록 $\mathrm{SBN}$ 의 세기도 증 가하므로 최근 신호대잡음비(signal-to-noise ratio)가 향상된 $3.0 \mathrm{~T}$ (tesla) 이상의 고자장의 장비를 이용한 fMRI 연구에서 $\mathrm{SBN}$ 의 영향에 대한 중요성이 더욱 부각되고 있다.

이러한 $\mathrm{SBN}$ 의 부정적인 영향을 최소화하기 위한 방법으로 는 현재까지 크게 두 가지 방법이 단독 혹은 복합적으로 사용 되고 있다. 첫째, 귀마개 혹은 헤드폰 착용으로 $\mathrm{SBN}$ 을 수동적 차폐시키는 방법이나 이는 $\mathrm{SBN}$ 에 대해 최대 $37.8 \pm 4.6 \mathrm{~dB}$ 정 도의 차폐효과만 있어 대개 100 130 dBSPL에 달하는 SBN 을 충분히 차단하지 못한다. ${ }^{3)}$ 둘째로 영상주기(repetition time, $\mathrm{TR}$ )를 8 10초 이상으로 길게 하고 기능적 영상 슬라이스들 을 짧은 한 기간 내에 몰아서 한 번에 찍음으로써 영상주기 내 에 조용한 기간을 확보하는 방법이다. 즉, 경사자장소음 $(\mathrm{SBN})$ 의 발생 후 그 소음의 영향이 모두 사라질 만큼 긴 시간의 간 격을 두어 영상신호에 최소한 반영되도록 하고, EPI 볼륨의 모 든 슬라이스들을 짧은 기간에 몰아서 획득함으로써 경사자장 소음의 발생시간을 최소화하는 sparse temporal acquisition (STA) 기법이다.) 이와 대조적으로 continuous acquisition(CA) 기법은 2 3초의 짧은 영상주기(TR)를 가능한 많이 반복하여 짧은 시간 내에 많은 $\mathrm{EPI}$ 를 획득함으로써 시간적 효율성 및 해상도를 극대화한다는 장점 때문에 fMRI 연구에 가장 널리 사용되어 왔다. 본 연구는 광대역의 자극 음으로 구성된 클래 식 음악의 청각자극에 의해 유발된 청각 피질 및 피질하 청각 중추의 활성화 정도에 대한 두 영상기법의 차이를 비교함으로 써 $\mathrm{SBN}$ 의 영향을 조사하고자 하였다. 또한 두 기법의 결과 차 이가 $\mathrm{SBN}$ 의 효과 때문인지 혹은 $\mathrm{CA}$ 에서 얻어지는 상대적으 로 더 많은 데이터량(sample size effect)에서 기인한 것인지 알기 위해 STA를 그와 볼륨 수를 맞춘 volume-matched CA
데이터(CAm)와 비교하였고, $\mathrm{CA}$ 와 $\mathrm{CAm}$ 의 비교를 통해 sample size 차이의 효과도 조사하였다.

\section{대상 및 방법}

이과학 및 신경학적 질환이 없는 순음청각역치 검사상 정상 청력[0.25 8 kHZ에서 $25 \mathrm{~dB} \mathrm{HL}$ (hearing level) 이내]으로 불 쾌역치수준(loudness discomfort level)과 가청역동범위(dynamic range) 검사에서 청각과민증이 없는 경우를 연구대상

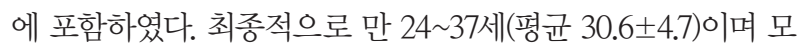
두 오른손잡이인 성인 14명(남: 8 명, 여: 6명)에 대해 연구가 시 행되었다. 본 연구는 본원 생명의학연구윤리위원회의 승인을 받았으며 실험 전에 모든 피검자가 연구 참여 동의서에 서명 제 출한 후 시행되었다.

\section{Acoustic stimulation}

청각자극은 블록디자인(block design)으로 구성하여 36초 를 하나의 블록으로 하였다. 한 블록 동안의 연속적인 자극음 으로 청각 중추의 반응을 중첩 및 지속시켜 강한 blood oxygen level-dependent(BOLD) 신호반응이 유지되도록 설정하 였다. 자극음은 36 초 간격으로 on/off를 반복하였고, 환자는 눈을 감고 수동적으로 양측 귀에 전해지는 자극음을 청취하도 록 하였다. 자극음으로는 음대역이 0.040 33 kHz인 클래식 음악을 사용하였다. 순음이나 백색잡음이 일차 청각피질(Heschl's gyrus, HG)에 국한된 활성화를 유도하는 데 비해 멜로디 가 있는 음악은 $\mathrm{HG}$ 외에도 이차 청각피질[planum temporale(PT), planum polare(PP)]과 superior temporal gyrus(STG) 등 전반적인 청각피질 영역의 반응을 유발하는 것으로 알려져 있다. ${ }^{5)}$ 자극음은 개인용 컴퓨터 프로그램인 Goldwave(Goldwave Inc., St. John's, NL, Canada)로 제작된 WAV 포맷의 파 일로 MRI 스캐너에 연결된 자극시스템인 E-Prime 1.2버전 프 로그램(Psychology Software Tools Inc., Pittsburgh, PA, USA) 을 통해 영상 주기와 동기화하였다. 발생한 자극음은 shielded electrodynamic cable을 통해 피검자의 헤드폰으로 전달되었 다. 피검자에 전달되는 자극음은 헤드폰 내부의 optical microphone을 통해 수신되어 Audiotester 2.1a 프로그램(Ulrich W. Mueller, Wuppertal, Germany)으로 자극음의 주파수와 크기 를 출력하였다. ${ }^{3)}$

\section{Image acquisition}

기능적 영상 1 run(6분) 동안 음자극 블록-휴식(무음)블록이 각각 36초인 주기를 5 회 반복하여 각 피검자에 모두 4 회의 run 을 반복 시행하였다. 모든 피검자는 32채널 Philips SENSE 
head coil을 가지고 있는 3.0-T MRI 스캐너(Philips Achieva, Philips Healthcare, Best, the Netherlands) 안에 반듯이 누 워 촬영에 임하였다. 피검자의 예기치 않은 비상상황을 대비하 고 외부와의 의사소통을 위해 손에 쥘 수 있는 보호버튼(nurse button)을 모든 피검자에게 제공하였고, 언제라도 피검자 의 의사에 따라 실험을 중단할 수 있도록 하였다. 기능적으로 얻은 영상을 공통의 뇌정위적 공간 안에 정규화시키기 위한 관상면 3D T1 이미지를 촬영하였다[TR=9.9 ms; echo time(TE)= $3.6 \mathrm{~ms}$; flip angle $(\mathrm{FA})=8^{\circ}$; slice thickness $=1.0 \mathrm{~mm}$; matrix= $256 \times 256 \times 195$; field of view $(\mathrm{FOV})=220 \mathrm{~mm}$; voxel size $=0.94 \times$ $0.94 \mathrm{~mm}$ ). 기능적 자기공명영상은 30 슬라이스의 T2* single shot EPI를 비스듬한 관상면(oblique coronal)으로 설정하여 획득하였다 (TE=35 ms; FA= 90; slice thickness $=5 \mathrm{~mm}, 1$ mm gap; matrix=80 $\times 79$; FOV=220 mm; voxel size $=2.75 \times$ $2.75 \mathrm{~mm}$ ). 위상부호화 방향(phase encoding sequence)은 오 른쪽에서 왼쪽으로 설정하였고 앞에서부터 19번째 슬라이스 에 하구(inferior colliculus, IC)와 와우핵(cochlear nucleus, $\mathrm{CN}$ )이 동시에 포함되도록 EPI 슬라이스의 plane(각도와 위 치)을 설정하였다.

$\mathrm{CA}$ 방법을 이용한 EPI 획득은 총 4회의 run 중 연속된 2개 의 run으로 구성하였다. TR을 2초로 설정하여 이미지를 획득 하는 동안 $\mathrm{SBN}$ 은 중단없이 지속적으로 발생하였고, 1 run 동 안 180 volumes의 이미지를 촬영하여 총 360개의 image volumes를 얻었다(TR=2 s, 180 volumes in each run). STA 방 법을 이용한 $\mathrm{EPI}$ 획득은 $\mathrm{TR}$ 을 12초로 설정하여서 $\mathrm{SBN}$ 사이 에 약 10 초 정도의 조용한 기간을 확보하였으며, 1 run 동안 30 volumes의 이미지를 촬영하여 총 60개의 image volumes를 얻었다(TR=12 s, 30 volumes in each run). $\mathrm{SBN}$ 외의 환경 소
음을 최소화하기 위해 image를 획득하는 시간 동안에는 냉각 펌프의 가동을 정지시켰다. CA에서 획득한 360 volumes의 EPI 와 STA에서 얻은 60 volumes의 결과들을 통계 처리하여 비 교하려면 $\mathrm{SBN}$ 의 유무 외에도 6 배의 데이터량의 차이에 의해 발생하는 sample size 효과가 존재하므로 이 두 효과를 분리해 서 조사해야 한다. 데이터량의 차이에 따른 효과를 제거해 순 수한 SBN 효과만을 조사하기 위해서 이미 얻은 $\mathrm{CA}$ 데이터의 전체 volume 중 6의 배수 간격으로 획득된 EPI만 모아 STA 와 시간적 배열이 일치하는 총 60 개의 volumes로 구성된 새로 운 데이터 세트(CAm)를 만들었다(Fig. 1).

\section{Pre-processing of image data}

MATLAB 9.0(MathWorks, Natick, MA, USA) 프로그램과 연동하는 SPM2(Statistical Parametric Mapping, Wellcome Department of Cognitive Neurology, Institute of Neurology, University College London, UK) 프로그램을 사용하여 영상 데이터를 전처리하였다. Philips MRI 스캐너의 고유 영상 포맷 인 PAR 영상파일들을 MRIcro(http://www.sph.sc.edu/comd/ rorden) 프로그램을 사용하여 분석을 위한 16-bit Analyze 영 상포맷으로 변경하였다. 영상획득 기간 중 발생한 머리움직임 (head motion)을 교정하기 위해 위치 재정렬(realignment)을 시행하였고, STA 및 CA에서 각각 위치재정렬이 된 총 2개 run 의 모든 EPI들의 평균연산(mean operation)을 적용하여 한 개의 평균 $\mathrm{EPI}(\mathrm{mean} \mathrm{EPI})$ 를 생성하였다. 각 피검자의 평균 $\mathrm{EPI}$ 를 동일 피검자의 해부학적 $\mathrm{T} 1$ 영상에 정합(coregistration)하 였고, 이때 생성된 정합 파라메타(coregistration parameter) 를 위치 재정렬된 모든 EPI들에 적용하여 T1 영상에 정합시켰 다. 각 피검자의 T1 영상을 Montreal Neurological Institute

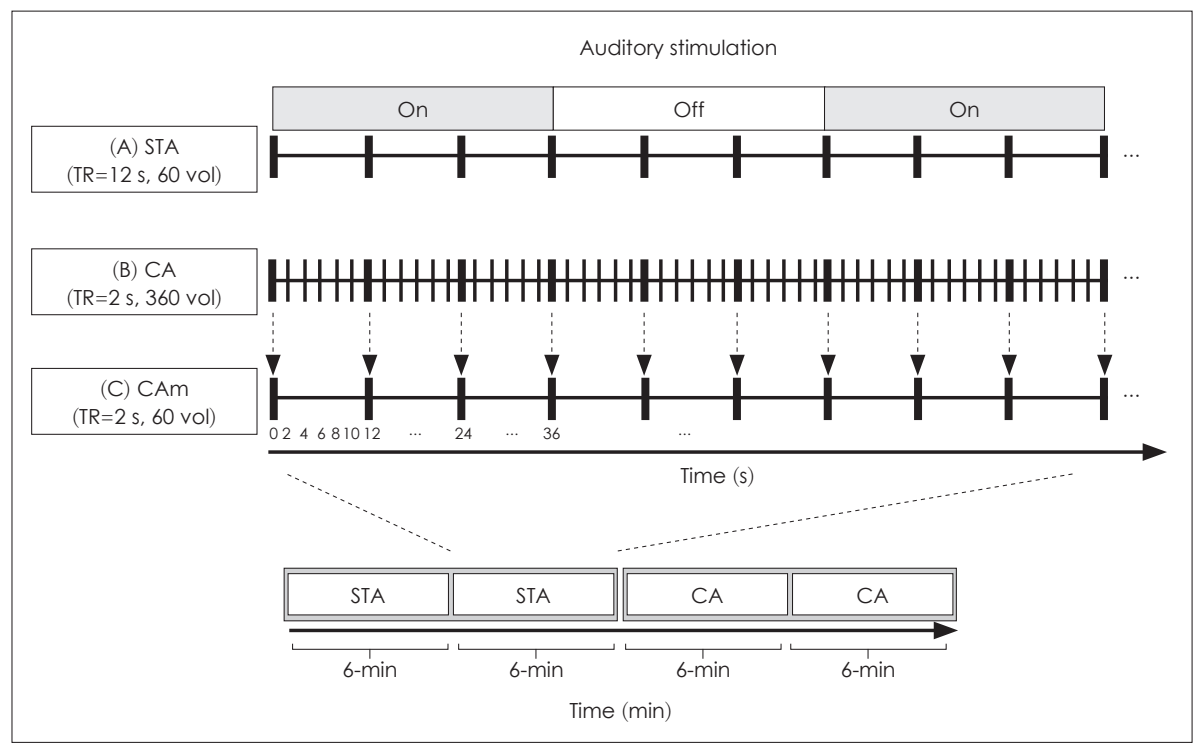

Fig. 1. Experimental design of auditory stimulation fMRI study. The auditory stimulus was presented in a block paradigm (36 s on/off). Each subject underwent two sparse temporal aquisitions (STA) and the other two continuous acquisitions (CA). In the STA, silent inter-scan interval was about $10 \mathrm{~s}$ resulting in the total of 60 dynamic scan volumes ( $T R=12 \mathrm{~s}, 30$ volumes per each run) (A). In the CA, a total of $360 \mathrm{dy}-$ namic scan volumes were continuously acquired with a TR=2 s (180 volumes per each run) with no silent gap between acquisitions (B). Volumematched continuous data set (CAm, 60 volumes) was generated by collecting every 6 th volume from the $\mathrm{CA}$, temporally matched to the volumes of STA (C). 
(MNI) 표준 T1원형 영상(template image)으로 공간정규화 (spatial normalization) 하였으며, 이때 생성된 공간정규화 파 라메타를 위치 재정렬-정합된 모든 $\mathrm{EPI}$ 들에 적용하여 공간 정규화를 시켰다. 최종적으로 영상의 신호대잡음비를 높이고, 데이터가 통계학적으로 정규분포를 이루도록 하기 위하여 8$\mathrm{mm}$ full-width at half-maximum isotropic Gaussian ker$\mathrm{nel}$ 을 위치 재정렬-정합-공간정규화된 $\mathrm{EPI}$ 들에 적용하여 공 간편평화(spatial smoothing)를 시행하였다. 영상의 전처리 과 정은 14 명의 모든 피검자의 데이터에 동일하게 적용하였으며, 전처리 과정을 통해 모든 피검자의 $\mathrm{EPI}$ 들이 공간적으로 같은 위치에 있게 되어 그룹분석이 가능하도록 하였다.

\section{Statistical analysis}

$\mathrm{fMRI}$ 의 통계분석은 SPM2를 사용하였고, 1 단계 그룹분석 에서는 일반선형모델(general linear model, GLM)의 다중회 귀분석법(multiple regression analysis)을 적용하여 분석하였 다. ${ }^{6} \mathrm{MRI}$ 스캐너 코일의 온도변화에 의한 자장신호의 불균질 성(inhomogeneity)에 의해 발생하는 EPI 신호의 전반적인 편 류교정(drift correction)을 위해 기준선(baseline), 선형(linear), 포물선(parabolic) 회귀상수를 각 run마다 GLM의 통제변수 (control variable)로 설정하였다. 대뇌 피질과 피질하 청각 중 추들[HG, PT, PP, 내측슬상체(medial geniculate body, MGB), $\mathrm{IC}, \mathrm{CN}]$ 을 관심영역(regions of interest, ROIs)으로 지정하고, 각 $\mathrm{ROI}$ 에서 가장 높은 활성화를 보이는 peak voxel을 중심으로 각각의 피검자에서 구조적 및 개별적으로 ROI의 범위를 정의 하였다. 그룹분석(random effects analysis)은 전체 피검자의
개인별 분석으로 얻어진 14 개의 BOLD 신호 활성화 지도(activation map)를 바탕으로 대조영상(contrast image)을 독립 변수로 하여 단일표본 t-test(one-sample t-test)를 적용하여 각 데이터 그룹의 $\mathrm{BOLD}$ 신호 활성화 지도를 만들었다. $\mathrm{CA}$ 와 $\mathrm{STA}, \mathrm{CA}$ 와 $\mathrm{CAm}$, 그리고 $\mathrm{CAm}$ 와 STA 사이의 비교는 각 그 룹분석에서 얻어진 $\mathrm{BOLD}$ 신호 활성화 지도를 바탕으로 각각 의 활성화된 정도의 차이를 이용하여 얻어진 $\mathrm{BOLD}$ 신호 활 성화 지도에서 $\mathrm{ROI}$ 의 $\mathrm{BOLD}$ 신호 강도를 단일표본 t-test를 적용하여 분석하였고, 통계적 유의수준은 false discovery rate $(\mathrm{FDR}) \mathrm{q}<0.05$ 로 결정하였다. 뇌척수액 영역은 분석에서 제외 하였고, $\mathrm{fMRI}$ 의 그룹분석결과는 전체 피검자 $\mathrm{T} 1$ 영상을 $\mathrm{MNI}$ 표준공간으로 공간정규화를 한 후에 만든 평균 영상에 덧씨 워(overlaid) 출력하였다.

다음 단계로 개인별 $\mathrm{ROI}$ 분석을 시행하여 $\mathrm{STA}, \mathrm{CA}$ 와 $\mathrm{CAm}$ 사이에 다음 변수들을 각 ROI별로 비교하였다. ${ }^{7-9)}$

- 신호강도변화량(Percent signal change, PSC)=100×(signal intensity during stimuli periods-signal intensity during resting periods)/signal intensity during resting periods

- 영상신호의 안정성을 의미하는 신호변이량(Signal variability)=standard deviation of signal intensity during stiumlation on and off

끝으로 $\mathrm{T}-$ 통계값은 일반선형모델으로 얻은 활성화 지도상 에서 구한 각 $\mathrm{ROI}$ 의 평균값을 취하였다. STA, CA와 CAm에 서 각각 개인별로 구해진 PSC, T-통계값과 signal variability 를 Kruskal-Wallis 및 multiple comparison test를 통해 통계 적 유의수준은 $p<0.05$ 로 비교하였다.

\section{$3.0 \square 8.0$}

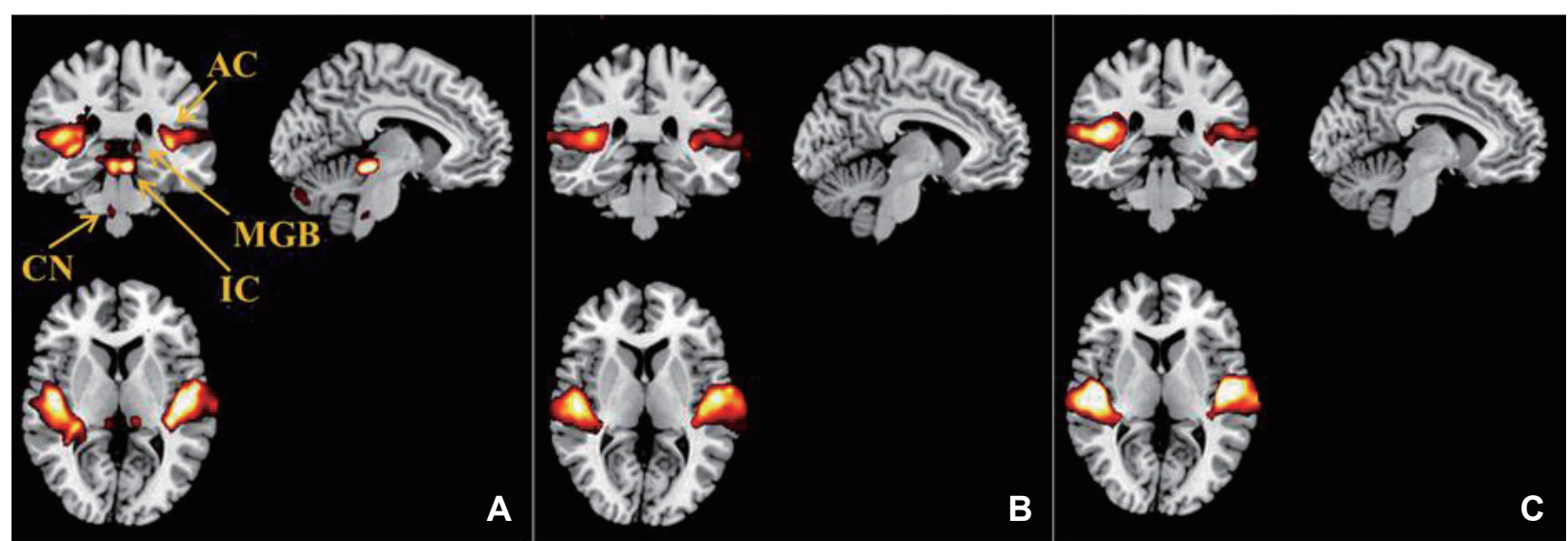

Fig. 2. General linear model analysis of the three datasets: auditory stimulus-evoked activation maps from the two experimental designs (STA and CA) and the subset CAm. In the STA, auditory stimulation by classic music resulted in activation in all auditory areas (cortical and subcortical) (A). In the CA and CAm, primary auditory cortex including HG, PT, and PP has been activated; however, no activation above the significance threshold was observed in the subcortical auditory nuclei (MGB, IC, and CN) (B and C). STA: sparse temporal acquisition, CA: continuous acquisition, CAm: STAmatched continuous acquisition volumes, AC: auditory cortex, MGB: medial geniculate body, IC: inferior colliculus, CN: cochlear nucleus, HG: Heschl's gyrus, PT: planum temporale, PP: planum polare. 

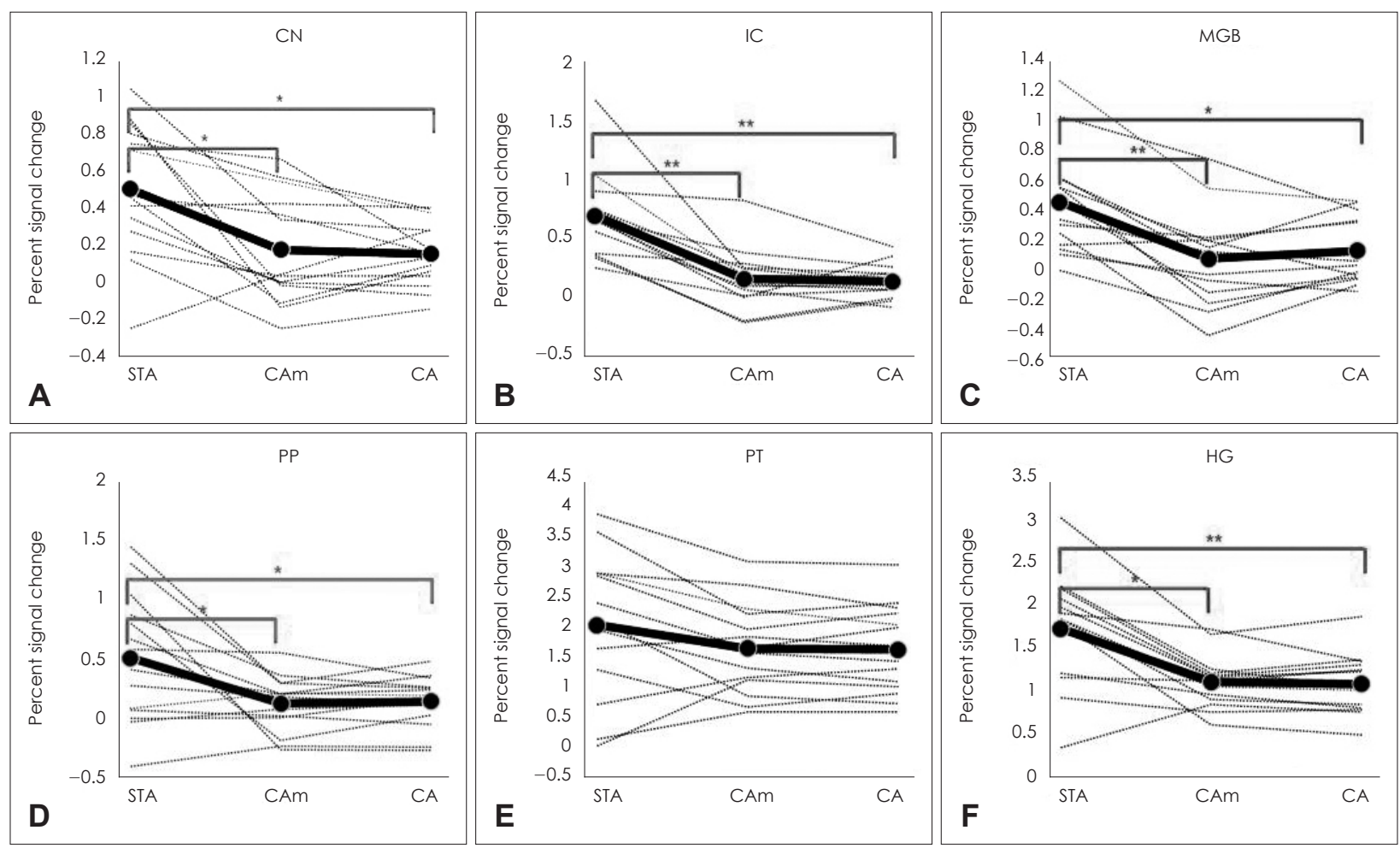

Fig. 3. Comparison of percent signal change between the three datasets. In the STA, CN, IC, MGB, PP, and HG showed higher percent signal change than in CA and CAm (A-D, and F). There was no difference of percent signal change amomg the three datasets in PT (E). ${ }^{*} p<0.05,{ }^{* *} p<0.01$. STA: sparse temporal acquisition, CA: continuous acquisition, CAm: STAmatched continuous acquisition volumes, HG: Heschl's gyrus, PT: planum temporale, PP: planum polare, MGB: medial geniculate body, IC: inferior colliculus, CN: cochlear nucleus.

\section{결 과}

최대한 SBN의 영향을 배제한 STA 기법은 그룹분석 결과에 서 모든 청각피질 및 피질하 청각 중추에서 BOLD 신호 활성 화가 관찰되었으나 연속적 영상획득기법인 CA와 CAm에서는 청각피질인 $\mathrm{HG}, \mathrm{PT}, \mathrm{PP}$ 만 활성화가 관찰되고 피질하중추인 $\mathrm{MGB}, \mathrm{IC}, \mathrm{CN}$ 의 활성화는 관찰되지 않았다(Fig. 2). ROI 분석 에서 청각자극에 의한 신호강도변화량(PSC)도 STA가 planum temporale(PT, 이차 청각피질)를 제외한 모든 ROI들에 서 CA와 CAm보다 유의하게 높은 값을 보였다(Fig. 3). T 통 계값(T-statistic value)도 STA가 PT를 제외한 모든 ROI에서 $\mathrm{CAm}$ 와 비교하여 유의하게 높은 값을 보였다(Fig. 4). 하지만 $\mathrm{STA}$ 의 T 통계값을 $\mathrm{CA}$ 와 비교할 때 대부분의 $\mathrm{ROI}$ 들에서 차 이가 없었으나 IC에서는 STA가, PT에서는 CA가 더 높은 값 을 보였다. Sample size 효과만을 반영하는 CA와 CAm의 비 교에서 $\mathrm{T}$ 통계값은 피질하 중추들에서는 차이가 없었지만 청 각피질들 $(\mathrm{HG}$ 와 $\mathrm{PT}$ )에서는 $\mathrm{CA}$ 가 더 높은 값을 보였다(Fig. 4). 음자극이 있을 때와 없을 때의 signal variability를 분석 했을 때, 모든 ROI들에서 STA, CA와 CAm 간의 차이를 관 찰할 수 없었다(Fig. 5).
고 찰

$\mathrm{SBN}$ 이 청각 중추 활성화에 미치는 영향을 STA 기법과 $\mathrm{CA}$ 기법의 비교를 통해 조사한 선행 연구결과들을 살펴보면 $\mathrm{CA}$ 에 비해 STA에서 $\mathrm{HG}$ 를 포함한 일차 청각피질을 비롯하여 청 각피질 영역들에서 자극음에 의한 활성도가 유의하게 증가하 는 것이 밝혀졌으며, ${ }^{10,11)}$ 이는 청각자극이전에 이미 $\mathrm{SBN}$ 에 의 해서 청각피질의 기저신호수준(baseline signal level)이 증가 한 상태에서 청각자극이 추가됨으로써 오히려 청각피질의 활 동이 포화(saturation)상태에 이르게 되므로 $\mathrm{SBN}$ 이 적은 STA 의 결과에 비해 $\mathrm{BOLD}$ 신호강도 변화량이 작게 나타나는 것 으로 설명할 수 있다. 즉, 지속적인 $\mathrm{SBN}$ 의 존재가 청각피질의 역동범위(dynamic range)를 축소시키는 교란인자로 작용한 다고 볼 수 있다. Gaab 등이의 연구에서는 일차 청각피질인 $\mathrm{HG}$ 에서 신호대잡음비가 STA에서 CA에 비해 높은 값을 보였고, HG 및 superior temporal gyrus(STG)에서 STA가 CA에 비 해 더 큰 신호강도변화량을 나타내었다. Blackman과 Hal1 ${ }^{11}$ 의 연구에서는 STA가 CA에 비해 HG, PT, 그리고 PP에서 음 자극시 더 높은 신호 강도를 보였다. 이에 반해 Peelle 등 ${ }^{12)}$ 은 음 자극시 발생하는 신호대잡음비를 비교하였을 때 STA와 CA 기법 사이의 차이가 없다는 연구도 발표하였다. 

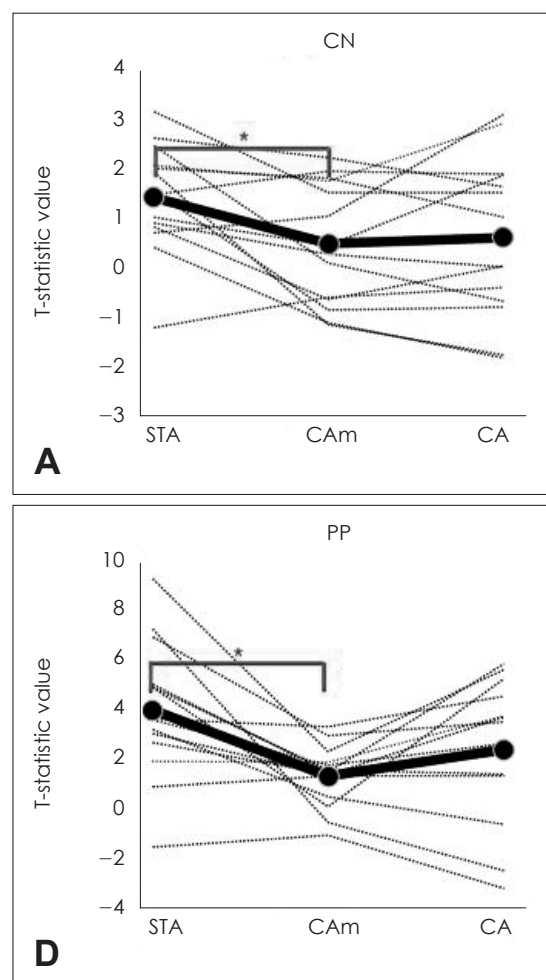
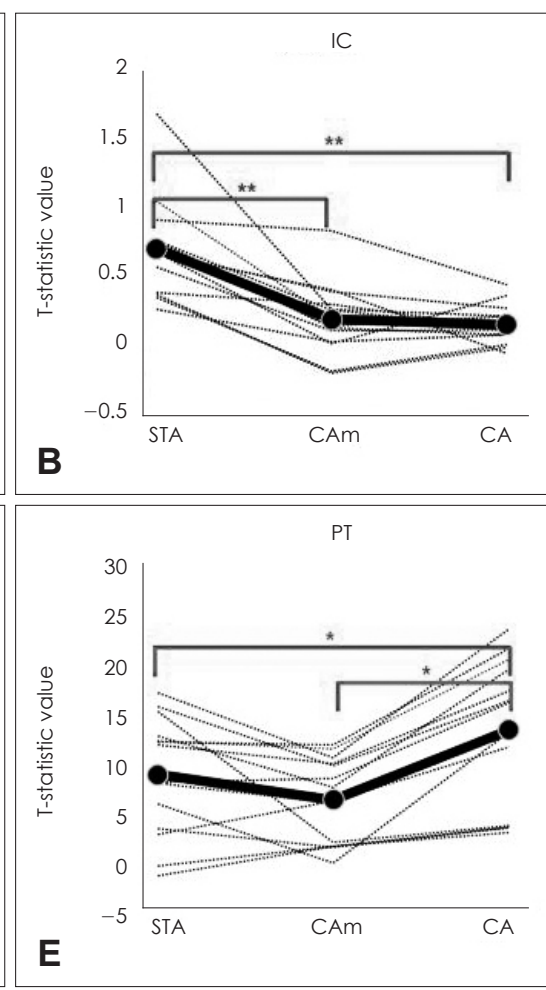
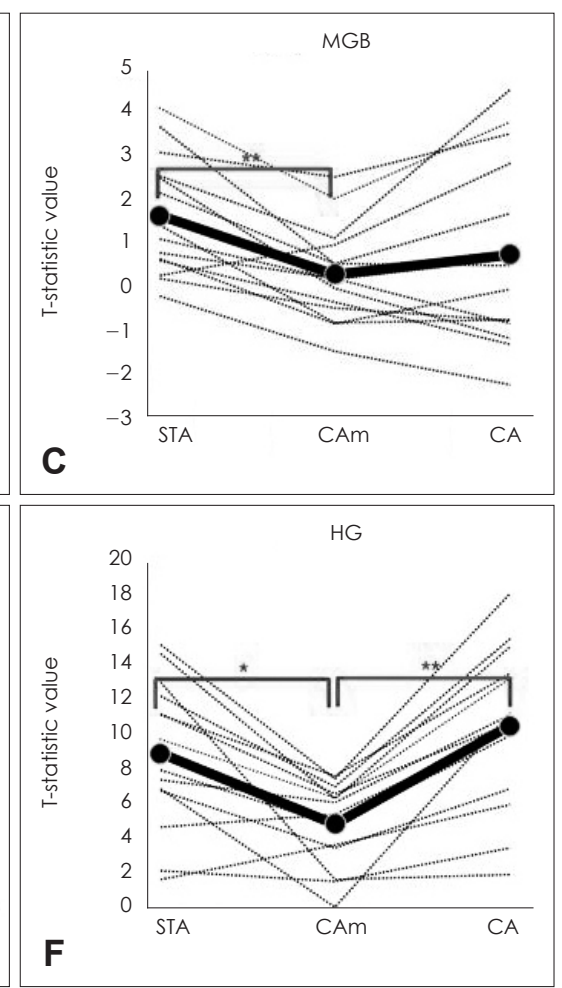

Fig. 4. Comparison of T-statistic values between the three datasets. In the STA, CN, MGB, and PP showed higher T statistics than in CAm (A, C, and D). In the STA, IC showed higher T statistics than in CA and CAm (B). In the CA, PT showed higher T statistics than in STA and CAm (E). In the CAm, HG showed lower T statistics than in STA and CA (F). ${ }^{*} p<0.05,{ }^{* *} p<0.01$. STA: sparse temporal acquisition, CA: continuous acquisition, CAm: STAmatched continuous acquisition volumes, HG: Heschl's gyrus, PT: planum temporale, PP: planum polare, MGB: medial geniculate body, IC: inferior colliculus, CN: cochlear nucleus.

현재까지 발표된 STA와 CA를 비교한 연구는 모두 청각피 질의 활성도만 분석한 제한점이 있었다(Table 1)..$^{10-12)}$ 본 연구 에서 $\mathrm{SBN}$ 은 청각피질보다 중뇌 및 뇌간의 피질하 청각 중추 의 활성화에 더 심각한 영향을 미치는 것으로 나타났다. 청각 fMRI 연구에서는 청각피질에서의 활성화뿐 아니라, 피질하 청각 중추에서의 신호 변화 분석도 중요하다. 본 연구결과에서 피질하 중추가 더 $\mathrm{SBN}$ 의 영향을 받는 것은 그 신호변화량(PSC) 의 절대값이 $0.5 \%$ 내외로 1 2\% 이상을 보이는 청각피질보다 훨씬 작아 $\mathrm{SBN}$ 과 같은 변수가 작용할 때 통계역치 이하로 PSC 값이 쉽게 떨어지기 때문인 것으로 생각된다. 피질하 청각 중 추의 신호변화량 절대값이 작은 이유는 그 구조물의 크기가 작 고 뇌간에 존재하여 인접한 기저동맥 박동의 영향으로 영상신 호가 피질보다 크게 교란되어 신호대잡음비가 낮기 때문이다. 하지만 청각자극방법, 영상획득 및 분석방법을 개선함으로써 청각 fMRI 연구의 난점을 해결하고, 청각피질 및 피질하 청각 중추의 신경활성화를 검출하기 위해 보다 쉽게 적용할 수 있는 프로토콜이 제시되어 성공적인 피질하 청각 중추에 대한 청각 fMRI 연구가 시행되고 있다. ${ }^{13)}$ 본 연구결과에서 알 수 있듯이 $\mathrm{STA}$ 는 영상주기를 길게 하여 길어진 영상 주기내에서 $\mathrm{SBN}$ 의 영향을 최소화함으로써 음자극에 더 효과적으로 반응할 수 있
게 한다. 음자극 후 발생하는 혈역학적 반응(hemodynamic response)은 4 7초 동안의 시간 간격을 두고 최대치에 도달하고 10 12초 후에 소멸하므로, STA로 영상주기를 연장하면 SBN 에 의해 유도된 혈역학적 변화를 회피할 수 있고 이보다 뒤늦 게 음자극에 의해 발생한 혈역학적 반응만을 영상에 반영시킬 수 있다. 그러나 STA의 가장 큰 단점은 영상주기가 길어 일정 한 검사 시간 동안 획득할 수 있는 영상의 양이 작아 기대한 혈 역학적 반응을 자주 반복하여 유도할 수 없으므로 정보 제공 량이 적어 분석시의 통계적 검증력이 약해지며, 시간의 흐름에 따른 정보를 제공받을 수 없다는 점이다. ${ }^{14)}$

이러한 STA의 단점을 극복하기 위한 방법으로 STA의 변형 기법 중 하나인 interleaved silent steady state(ISSS) 방법이 있다. ${ }^{15)} \mathrm{ISSS}$ 는 CA와 STA를 적절히 혼합한 방법으로 STA와 같이 음자극시에는 영상을 찍지 않아 $\mathrm{SBN}$ 이 최대한 제거된 상태에서 자극을 받도록 하고, 음자극이 끝났을 때는 MR이 안 정상태 선형 자화(steady state longitudinal magnetization) 를 유지하도록 하여 TR 사이에 여러 개의 영상을 얻을 수 있도록 하는 기법이다. ISSS는 STA에 비교하여 통계 검증력도 강화되 고, TR내에서 $\mathrm{BOLD}$ 신호의 시간에 따른 변화 양상에 대한 정 보도 제공해 주는 장점이 있어 현재 청각 fMRI 연구에 다양하게 


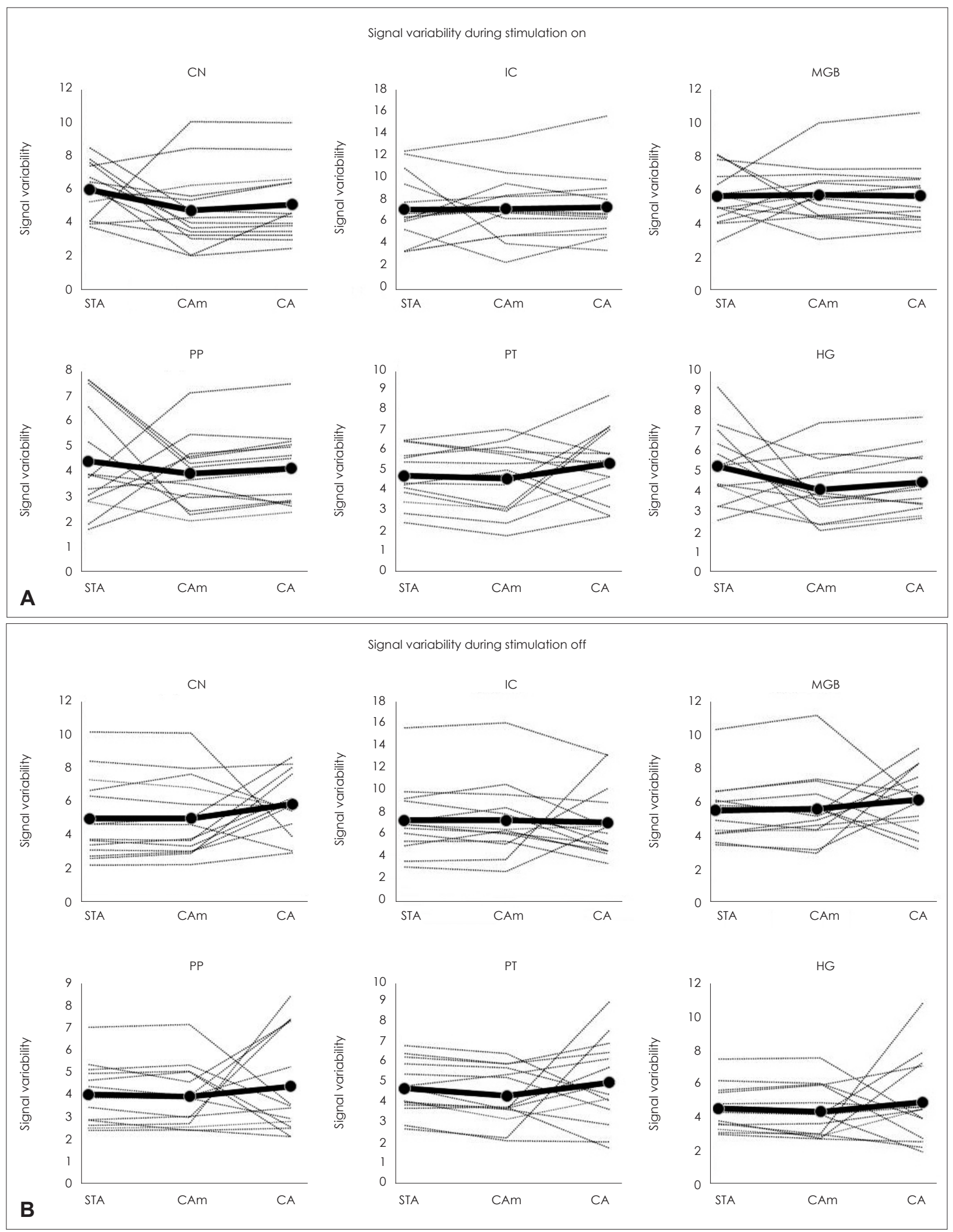

Fig. 5. Comparison of signal variability during stimulus-on and stimulus-off periods between the three datasets. There was no difference of signal variability during stimulation-on $(\mathrm{A})$ and -off $(\mathrm{B})$ among the three datasets. STA: sparse temporal acquisition, CA: continuous acquisition, CAm: STAmatched continuous acquisition volumes, HG: Heschl's gyrus, PT: planum temporale, PP: planum polare, MGB: medial geniculate body, IC: inferior colliculus, CN: cochlear nucleus. 
Table 1. Summary of auditory fMRI studies on STA and CA comparison

\begin{tabular}{|c|c|c|c|c|c|c|}
\hline Study & Subjects & $\begin{array}{c}\text { CA } \\
\text { sequence/volumes }\end{array}$ & $\begin{array}{c}\text { STA } \\
\text { sequence/volumes }\end{array}$ & Scanner & Stimulus & Results \\
\hline$\overline{G a a b}$, et al. ${ }^{10)}$ & $\begin{array}{l}\text { Ten healthy } \\
\text { right handed } \\
\text { adults }\end{array}$ & $\begin{array}{l}\mathrm{EPI}, \mathrm{TR}=2 \mathrm{~s}, \mathrm{TE}=30 \mathrm{~ms}, \\
\mathrm{FA}=75^{\circ}, 30 \text { slices, } \\
516 \text { volumes }\end{array}$ & $\begin{array}{l}\mathrm{EPI}, \mathrm{TR}=16 \mathrm{~s}, \mathrm{TE}=30 \mathrm{~ms}, \\
\mathrm{FA}=90^{\circ}, 30 \text { slices, } \\
66 \text { volumes }\end{array}$ & $\begin{array}{l}\text { General } \\
\text { Electronics } 3 \\
\text { Tesla Signa }\end{array}$ & $\begin{array}{l}\text { One-syllable } \\
\text { words spoken } \\
\text { by a female }\end{array}$ & $\begin{array}{l}\text { SNR: } S T A>C A \\
\text { in HG, } \\
\text { no difference } \\
\text { in STG } \\
\text { PSC: STA }>C A \\
\text { in HG and STG }\end{array}$ \\
\hline Peelle, et al. ${ }^{12)}$ & $\begin{array}{l}\text { Six healthy } \\
\text { right handed } \\
\text { adults }\end{array}$ & $\begin{array}{l}\mathrm{EPI}, \mathrm{TR}=2.8 \mathrm{~s}, \mathrm{TE}=30 \mathrm{~ms}, \\
\mathrm{FA}=90^{\circ}, 32 \text { slices, } \\
284 \text { volumes }\end{array}$ & $\begin{array}{l}\mathrm{EPI}, \mathrm{TR}=11.2 \mathrm{~s}, \mathrm{TE}=30 \mathrm{~ms} \\
\mathrm{FA}=90^{\circ}, 32 \text { slices, } \\
71 \text { volumes }\end{array}$ & $\begin{array}{r}\text { Siemens } 3 \\
\text { Tesla Trio }\end{array}$ & $\begin{array}{l}\text { Signal correlated } \\
\text { noise and } \\
\text { speech }\end{array}$ & SNR: no difference \\
\hline $\begin{array}{l}\text { Blackman and } \\
\text { Hall }^{11)}\end{array}$ & $\begin{array}{l}\text { Eight healthy } \\
\text { right handed } \\
\text { adults }\end{array}$ & $\begin{array}{l}E P I, T R=3 \mathrm{~s}, \mathrm{TE}=36 \mathrm{~ms}, \\
\mathrm{FA}=90^{\circ}, 32 \text { slices, } \\
190 \text { volumes }\end{array}$ & $\begin{array}{l}E P I, T R=9 \mathrm{~s}, \mathrm{TE}=36 \mathrm{~ms}, \\
\mathrm{FA}=90^{\circ}, 32 \text { slices, } \\
68 \text { volumes }\end{array}$ & $\begin{array}{l}\text { Philips } 3 \\
\text { Tesla Intera }\end{array}$ & $\begin{array}{l}\text { Narrowband } \\
\text { noise and } \\
\text { complex sounds } \\
\text { (speech) }\end{array}$ & $\begin{array}{l}\text { PSC: } S T A>C A \\
\text { in } H G, P T \text {, and PP }\end{array}$ \\
\hline Present study & $\begin{array}{l}\text { Fourteen } \\
\text { healthy right } \\
\text { handed } \\
\text { adults }\end{array}$ & $\begin{array}{l}E P I, T R=2 s, T E=35 \mathrm{~ms}, \\
F A=90^{\circ}, 30 \text { slices, } \\
180 \text { volumes }\end{array}$ & $\begin{array}{l}\mathrm{EPI}, \mathrm{TR}=12 \mathrm{~s}, \mathrm{TE}=35 \mathrm{~ms}, \\
\mathrm{FA}=90^{\circ}, 30 \text { slices, } \\
60 \text { volumes }\end{array}$ & $\begin{array}{l}\text { Philips } 3 \\
\text { Tesla Achieva }\end{array}$ & Classic music & $\begin{array}{l}\text { PSC: STA >CA } \\
\text { in all ROIs, } \\
\text { especially } \\
\text { in the subcortical } \\
\text { auditory nuclei }\end{array}$ \\
\hline
\end{tabular}

fMRI: functional MRI, STA: sparse temporal acquisition, CA: continuous acquisition, FA: flip angle, CNR: contrast-to-noise ratio, STG: superior temporal gyrus, HG: Heschl's gyrus, PT: planum temporale, PP: planum polare, SNR: signal-to-noise ratio, ROI: region of interest, EPI: echoplanar images, TR: repitition time, TE: echo time

시도되고 있다. ${ }^{16)}$ 하지만, 안정상태에서 얻어지는 영상 획득비 율(sampling rate)의 일관성이 없기 때문에 정보의 비연속성이 발생하여 얻어진 정보 분석에 한계가 있는 단점이 있어 아직 일반적인 청각 fMRI의 연구에 널리 사용되지 못하고 있다.

피질하 청각 중추는 뇌간에 존재하므로 인접한 기저동맥 박 동의 영향으로 구조물의 위치가 변하여 안정적으로 영상을 획 득하기가 어렵다. 이러한 문제점을 해소하기 위한 방법이 Cardiac gating이다. Cardiac gating은 피험자의 심박수를 모니터 링하여 영상 획득을 심장 박동과 동기화시키는 방법으로 심장 박동에 의한 잡음으로 발생되는 신호의 활성화를 감소시킨다. 이는 $\mathrm{IC}, \mathrm{MGB}$ 와 같은 피질하 청각 중추의 $\mathrm{BOLD}$ 활성화 관 찰를 용이하게 해준다. ${ }^{17)}$ 하지만 cardiac gating은 특별히 고안 된 영상 획득 방법 사용 및 얻어진 영상의 post-processing에 상당한 시간과 노력이 소모되어 fMRI 연구에 일반적으로 사 용하지는 못 한다. 최근 cardiac gating을 시행하지 않고도 STA 기법을 사용한 clustered volume acquisition을 통해 충분한 숫자의 피험자를 이용하여 피질하 청각 중추의 BOLD 활성화 가 관찰될 수 있음이 보고되었다. ${ }^{18)}$ 본 연구에서도 cardiac gating을 사용하지 않았지만 충분한 피험자 수와 음악을 이용한 음자극으로 STA에서 피질하 청각 중추의 활성화를 관찰할 수 있었다.

피질하 청각 중추에 대한 fMRI 연구 중, STA 기법을 사용하 여 피질하 청각 중추의 활성화를 연구한 결과는 연구자마다 조금씩 차이가 있지만, $\mathrm{IC}$ 의 활성화가 가장 잘 관찰되며 다음 으로 $\mathrm{MGB}, \mathrm{CN}$ 순으로 관찰되는 것으로 알려져 있다. ${ }^{19)}$ 본 연
구 결과에서 STA 기법을 사용하여 $\mathrm{MGB}, \mathrm{IC}$, 그리고 $\mathrm{CN}$ 모두 활성화가 관찰되었고, 피질하 청각 중추들의 $\mathrm{PSC}$ 를 비교하였 을 때 $\mathrm{IC}$ 가 가장 높고 다음으로 $\mathrm{MGB}, \mathrm{CN}$ 순이었다. 본 연구 에서 $\mathrm{CA}$ 에서는 음자극을 주었을 때 STA에 비해 피질하 청각 중추의 활성화가 저하된다는 것이 관찰되었고, 이러한 STA와 $\mathrm{CA}$ 의 결과 비교는 $\mathrm{SBN}$ 이 피질하 청각중추 활성화에 작용하 는 지대한 영향을 직접적으로 보여준다.

본 연구에서 $\mathrm{PSC}$ 값이 모든 $\mathrm{ROI}$ 에서 $\mathrm{CA}$ 보다 STA에서 높 은 값을 보였지만 $\mathrm{PT}$ 에서는 차이가 없었고, $\mathrm{T}$ 통계값에서는 CA가 STA에 비해 PT에서 오히려 더 높은 값을 보였다. PT에 서만 STA보다 T 통계값이 높게 나오는 이유로는 본 연구의 자 극음이 음악이었기 때문으로 생각된다. PT는 소음이나 순음 과 같은 의미없는 음자극보다 음악과 같은 의미있는 음자극에 더욱 활성화가 잘 되는 이차 청각 피질로 알려져 있다. ${ }^{20)} \mathrm{CA}$ 에 서는 지속적인 $\mathrm{SBN}$ 이 들리는 가운데 음악을 들으려는 노력, 즉 자극음 청취에 대한 집중도를 높이는 결과를 가져와 조용 한 환경의 STA보다 CA에서 $\mathrm{PT}$ 와 같은 이차 청각 피질에 더 강한 반응이 보이게 된 것으로 추측된다.

$\mathrm{SBN}$ 의 영향을 최소화하는 $\mathrm{STA}$ 방법은 $\mathrm{CA}$ 에 비해 피질하 청각 중추의 활성화도 보여줄 수 있으면서 PSC, T-statics, 그 리고 signal variability와 같이 음자극시 발생하는 신호 변화 에 대한 반응도 $\mathrm{CA}$ 와 큰 차이가 없거나 더 높은 것으로 밝혀 졌다. 또한 ISSS나 cardiac gating 등의 방법을 추가로 사용하 지 않았음에도 STA만으로 피질 및 피질하 청각 중추의 BOLD 활성화를 관찰할 수 있었다. 따라서 향후 청각 fMRI 연구에 
있어 STA 방법을 사용함으로써 더 효율적인 청각 중추의 활 성화를 기대할 수 있을 것으로 생각된다.

\section{Acknowledgments}

This research was supported by Basic Science Research Program through the National Research Foundation of Korea (NRF) funded by the Ministry of Education (2014R1A1A4A01003909).

\section{REFERENCES}

1) Price DL, De Wilde JP, Papadaki AM, Curran JS, Kitney RI. Investigation of acoustic noise on $15 \mathrm{MRI}$ scanners from $0.2 \mathrm{~T}$ to 3 T. J Magn Reson Imaging 2001;13(2):288-93.

2) Van de Moortele PF, Cerf B, Lobel E, Paradis AL, Faurion A, Le Bihan D. Latencies in fMRI time-series: effect of slice acquisition order and perception. NMR Biomed 1997;10(4-5):230-6.

3) Nam EC, Kim SS, Lee KU, Kim SS. Development of sound measurement systems for auditory functional magnetic resonance imaging. Magn Reson Imaging 2008;26(5):715-20.

4) Hall DA, Haggard MP, Akeroyd MA, Palmer AR, Summerfield AQ, Elliott MR, et al. "Sparse” temporal sampling in auditory fMRI. Hum Brain Mapp 1999;7(3):213-23.

5) Patterson RD, Uppenkamp S, Johnsrude IS, Griffiths TD. The processing of temporal pitch and melody information in auditory cortex. Neuron 2002;36(4):767-76.

6) Friston KJ, Poline JB, Holmes AP, Frith CD, Frackowiak RS. A multivariate analysis of PET activation studies. Hum Brain Mapp 1996;4(2):140-51.

7) Eden GF, Joseph JE, Brown HE, Brown CP, Zeffiro TA. Utilizing hemodynamic delay and dispersion to detect fMRI signal change without auditory interference: the behavior interleaved gradients technique. Magn Reson Med 1999;41(1):13-20.

8) Arthurs OJ, Williams EJ, Carpenter TA, Pickard JD, Boniface SJ. Linear coupling between functional magnetic resonance imaging and evoked potential amplitude in human somatosensory cortex. Neuroscience 2000;101(4):803-6.

9) Arthurs OJ, Boniface SJ. What aspect of the fMRI BOLD signal best reflects the underlying electrophysiology in human somatosensory cortex? Clin Neurophysiol 2003;114(7):1203-9.

10) Gaab N, Gabrieli JD, Glover GH. Assessing the influence of scanner background noise on auditory processing. I. An fMRI study comparing three experimental designs with varying degrees of scanner noise. Hum Brain Mapp 2007;28(8):703-20.

11) Blackman GA, Hall DA. Reducing the effects of background noise during auditory functional magnetic resonance imaging of speech processing: qualitative and quantitative comparisons between two image acquisition schemes and noise cancellation. J Speech Lang Hear Res 2011;54(2):693-704

12) Peelle JE, Eason RJ, Schmitter S, Schwarzbauer C, Davis MH. Evaluating an acoustically quiet EPI sequence for use in fMRI studies of speech and auditory processing. Neuroimage 2010;52(4):1410-9.

13) Tae WS, Kim SS, Lee KU, Lee SH, Choi HK, Nam EC. Using fMRI to detect activation of the cortical and subcortical auditory centers: development of a standard protocol for a conventional 1.5-T MRI scanner. J Korean Soc Radiol 2009;61(5):279-89.

14) Robson MD, Dorosz JL, Gore JC. Measurements of the temporal fMRI response of the human auditory cortex to trains of tones. Neuroimage 1998;7(3):185-98.

15) Schwarzbauer C, Davis MH, Rodd JM, Johnsrude I. Interleaved silent steady state (ISSS) imaging: a new sparse imaging method applied to auditory fMRI. Neuroimage 2006;29(3):774-82.

16) Rodd JM, Johnsrude IS, Davis MH. Dissociating frontotemporal contributions to semantic ambiguity resolution in spoken sentences. Cereb Cortex 2012;22(8):1761-73.

17) Overath T, Zhang Y, Sanes DH, Poeppel D. Sensitivity to temporal modulation rate and spectral bandwidth in the human auditory system: fMRI evidence. J Neurophysiol 2012;107(8):2042-56.

18) Kovacs S, Peeters R, Smits M, De Ridder D, Van Hecke P, Sunaert S. Activation of cortical and subcortical auditory structures at $3 \mathrm{~T}$ by means of a functional magnetic resonance imaging paradigm suitable for clinical use. Invest Radiol 2006;41(2):87-96.

19) Langers DR, van Dijk P, Backes WH. Lateralization, connectivity and plasticity in the human central auditory system. Neuroimage 2005;28(2):490-9.

20) Schlaug G, Jäncke L, Huang Y, Steinmetz H. In vivo evidence of structural brain asymmetry in musicians. Science 1995;267(5198): 699-701. 